\title{
Preparation of Cylinder-Shaped Porous Sponges of Poly(L-lactic acid), Poly(DL-lactic-co-glycolic acid), and $\operatorname{Poly}(\varepsilon$-caprolactone $)$
}

\author{
Xiaoming He, Naoki Kawazoe, and Guoping Chen \\ Tissue Regeneration Materials Unit, International Center for Materials Nanoarchitectonics, \\ National Institute for Materials Science, 1-1 Namiki, Tsukuba, Ibaraki 305-0044, Japan \\ Correspondence should be addressed to Guoping Chen; guoping.chen@nims.go.jp
}

Received 13 December 2013; Accepted 17 January 2014; Published 27 February 2014

Academic Editor: Yoshihiro Ito

Copyright (C) 2014 Xiaoming He et al. This is an open access article distributed under the Creative Commons Attribution License, which permits unrestricted use, distribution, and reproduction in any medium, provided the original work is properly cited.

\begin{abstract}
Design of mechanical skeletons of biodegradable synthetic polymers such as poly(L-lactic acid) (PLLA), poly(DL-lactic-co-glycolic acid) (PLGA), and poly( $\varepsilon$-caprolactone) (PCL) is important in the construction of the hybrid scaffolds of biodegradable synthetic polymers and naturally derived polymers such as collagen. In this study, cylinder-shaped PLLA, PLGA, and PCL sponges were prepared by the porogen leaching method using a cylinder model. The effects of polymer type, polymer fraction, cylinder height, pore size, and porosity on the mechanical properties of the cylinder-shape sponges were investigated. SEM observation showed that these cylinder-shaped sponges had evenly distributed bulk pore structures and the wall surfaces were less porous with a smaller pore size than the wall bulk pore structures. The porosity and pore size of the sponges could be controlled by the ratio and size of the porogen materials. The PLGA sponges showed superior mechanical properties than those of the PLLA and PCL sponges. Higher porosity resulted in an inferior mechanical strength. The pore size and sponge height also affected the mechanical properties. The results indicate that cylinder-shaped sponges can be tethered by choosing the appropriate polymers, size and ratio of porogen materials and dimension of sponges based on the purpose of the application.
\end{abstract}

\section{Introduction}

Porous scaffolds have been used for three-dimensional cell cultures to construct functional tissues and organs for transplantation [1-4]. The porous scaffolds provide a temporary microenvironment for the seeded cells to control cell functions, provide sufficient space for new tissue formation, and protect cells from suppression by surrounding tissues. Various porous scaffolds have been developed from both synthetic and naturally derived polymers for tissue engineering and regeneration [5-12].

In addition to the ability to allow cell adhesion, promote cell proliferation and differentiation, assemble the cells and extracellular matrices, and guide the formation of functional tissues and organs, porous scaffolds should have high mechanical strength and high porosity $[13,14]$. However, porosity and mechanical strength are contradictory properties of porous scaffolds. Generally, high porosity results in low mechanical strength and vice versa. To solve the problem, biodegradable synthetic polymers such as poly(L-lactic acid) (PLLA), poly(glycolic acid) (PGA), poly(DL-lactic-coglycolic acid) (PLGA), and poly(e-caprolactone) (PCL) have been hybridized with naturally derived polymers such as collagen [15-19]. The mechanically strong synthetic polymers serve as a mechanical skeleton to support the hybrid porous scaffolds, whereas collagen sponges provide high porosity and a favorable microenvironment for cell proliferation and new tissue formation. We have used the hybridization method to prepare a new type of hybrid porous scaffolds by introducing collagen sponges into a cylinder-shaped PLLA sponge skeleton [20]. The cylinder-shaped PLLA-collagen hybrid sponges showed high mechanical strength and high 


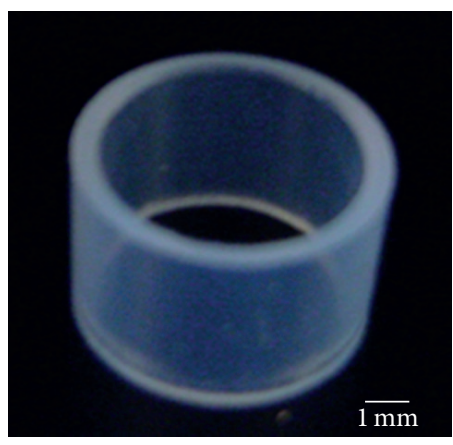

(a)

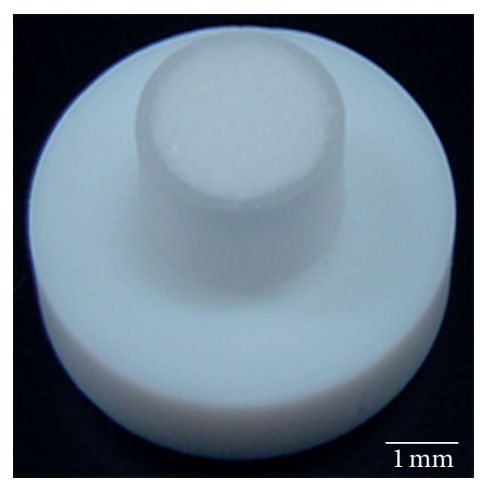

(d)

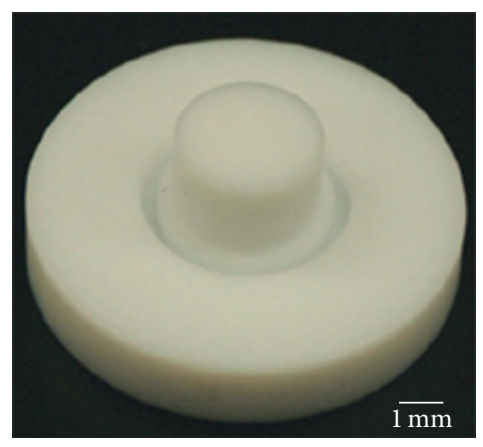

(b)

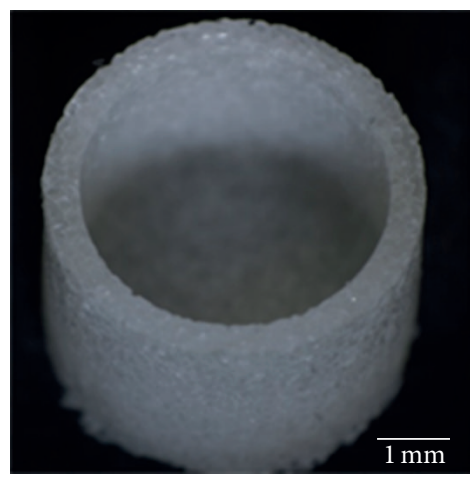

(e)

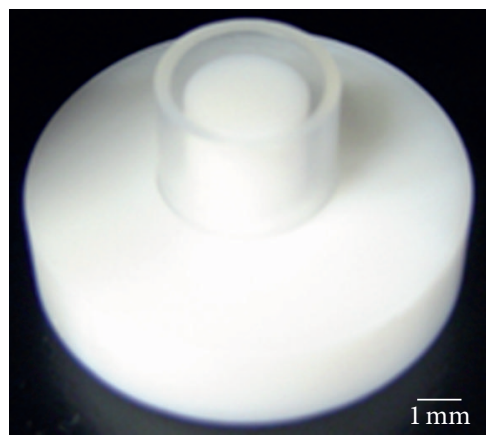

(c)

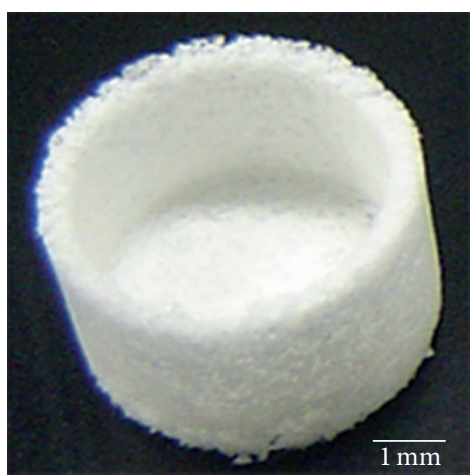

(f)

Figure 1: Photographs of the PFA tube (a), Teflon base (b), assembled Teflon mold (c), mixture of NaCl and PLLA filled within Teflon model (d), PLLA/NaCl cylinder (e), and cylinder-shaped PLLA sponge (f).

porosity. Compared to block-type hybrid sponges, cylindershaped PLLA-collagen hybrid sponges had a higher porosity $[10,20]$. The key technique in the construction of such cylinder-shaped hybrid sponges is to assemble the cylindershaped porous skeletons from mechanically strong synthetic polymers. Therefore, in this study, we compared three types of biodegradable polymers, PLGA, PLLA, and PCL, for the creation of a mechanically strong and stable cylindershaped porous skeleton. The effects of synthetic polymer type, cylinder size, and preparation conditions on the mechanical strength of the cylinder-shaped skeletons were investigated to provide important information for polymer selection and the construction of optimal porous scaffolds for tissue engineering.

\section{Experimental and Methods}

Cylinder-shaped sponges were prepared by the method of porogen leaching using a Teflon mold. The Teflon mold consisted of a perfluoroalkoxy (PFA) tube having an inner diameter of $12 \mathrm{~mm}$ and a height of $9 \mathrm{~mm}$ (Figure 1(a)) and a Teflon base having a pillar with a diameter of $10 \mathrm{~mm}$ and a height of $6 \mathrm{~mm}$ (Figure 1(b)). The PFA tube was plugged into the groove to construct the Teflon mold (Figure 1(c)). By using the Teflon mold, cylinder-shaped sponges having an inner diameter of $10 \mathrm{~mm}$, an outer diameter of $12 \mathrm{~mm}$, and a height of $7 \mathrm{~mm}$ can be prepared. Poly(L-lactic acid) (PLLA, weight-average molecular weight: 116,000 \pm 4700,
Sigma-Aldrich, Inc., St. Louis, MO) was used to prepare the cylinder-shaped PLLA sponges. The Tg of PLLA is $47^{\circ} \mathrm{C}$ [21]. PLLA (1 g) was dissolved in chloroform $(5 \mathrm{~mL})$ in a glass tube, to which sieved sodium chloride $(\mathrm{NaCl})$ particulates $(9 \mathrm{~g})$ were added and mixed well. Sieved $\mathrm{NaCl}$ particulates ranging between $90-150,150-250$, and $250-355 \mu \mathrm{m}$ were used to prepare the cylinder-shaped PLLA sponges with different pore sizes. The space between the PFA tube and the Teflon base of the Teflon mold was filled with the polymer solution/ $\mathrm{NaCl}$ mixture by pressing the mixture into the space. The pressed mixture above the PFA tube was removed by trimming the top surface (Figure $1(\mathrm{~d})$ ). The filled Teflon mold was dried in an air draft for 1 day and vacuum-dried for another 3 days to allow the chloroform to evaporate completely. After drying, the Teflon mold was disassembled to remove the cylinder of the polymer/ $\mathrm{NaCl}$ mixture from the Teflon mold (Figure $1(\mathrm{e})$ ). The polymer $/ \mathrm{NaCl}$ cylinder was immersed in deionized water to leach out the $\mathrm{NaCl}$ particulates. The deionized water was changed every hour. The washing was continued until the complete removal of $\mathrm{NaCl}$. The cylinder-shaped PLLA sponges were dried in air after washing (Figure $1(\mathrm{f})$ ).

The weight ratio of PLLA to $\mathrm{NaCl}$ particulates was adjusted at $1: 4,1: 5,1: 6,1: 7,1: 8$, and $1: 9$ to prepare cylindershaped PLLA sponges of different porosity. Either 4, 5, 6, 7, 8, or 9 grams of the sieved sodium chloride $(\mathrm{NaCl})$ particulates, with a diameter ranging from 150 to $255 \mu \mathrm{m}$, was added to the PLLA solution in chloroform $(1 \mathrm{~g} / 5 \mathrm{~mL})$ and mixed well. The following steps were the same as those described above. 


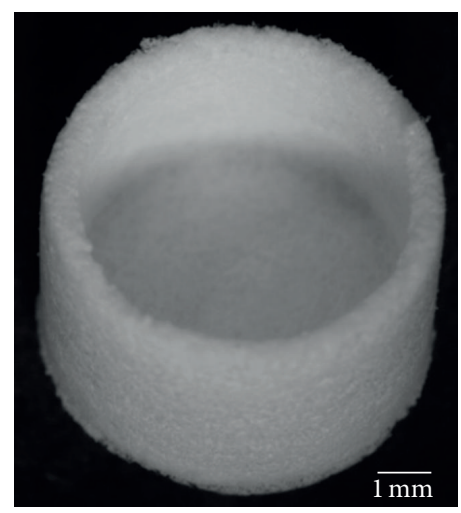

(a)

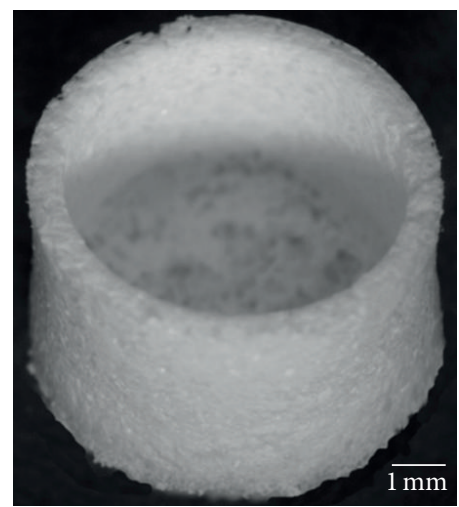

(d)

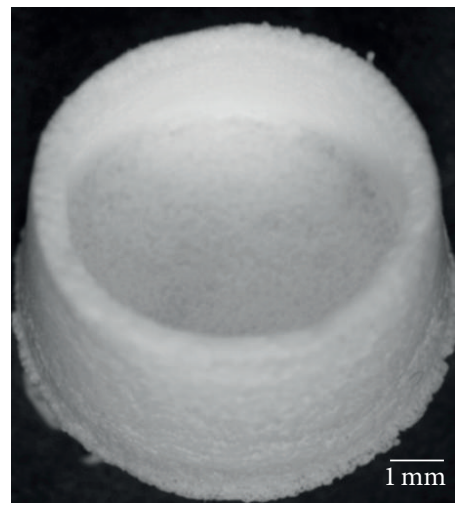

(g)

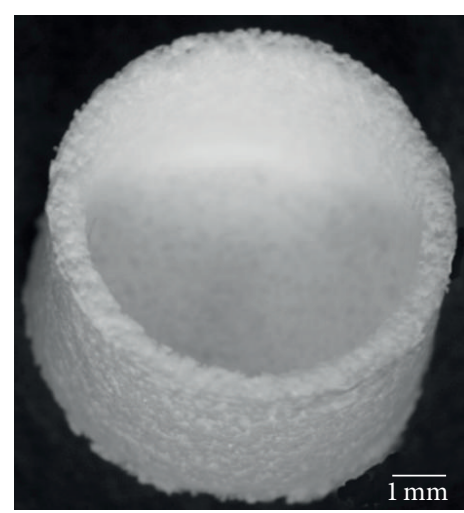

(b)

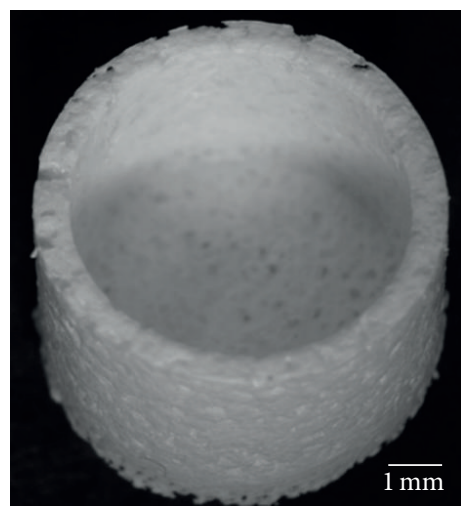

$(\mathrm{e})$

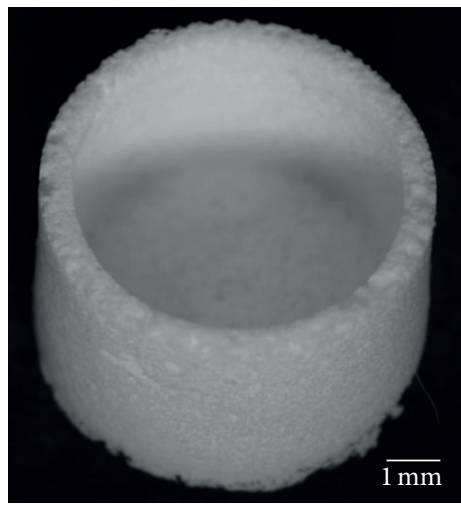

(h)

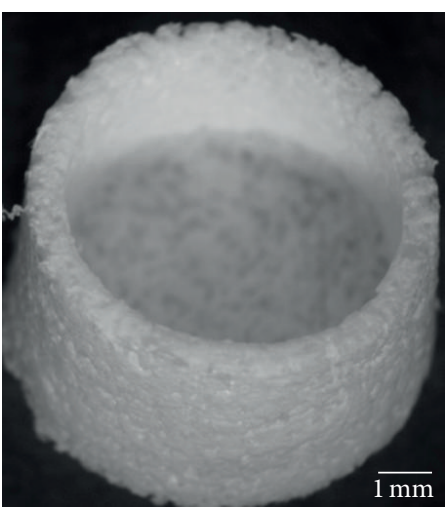

(c)

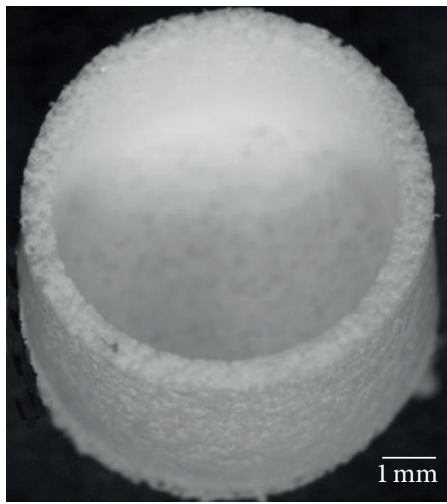

(f)

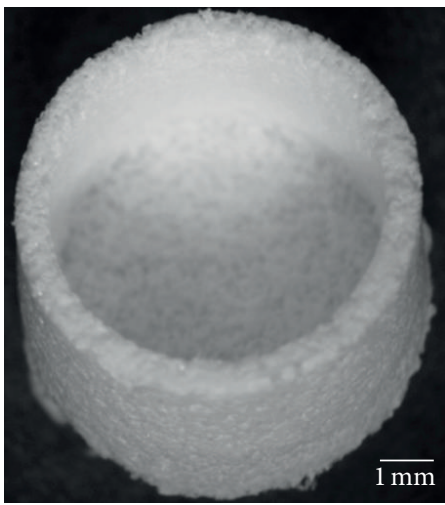

(i)

FIGURE 2: Photographs of cylinder-shaped PLLA (a-c), PLGA (d-f), and PCL ( $\mathrm{g}-\mathrm{i}$ ) sponges prepared with NaCl particulates having a diameter range of $90-150 \mu \mathrm{m}$ (a, d, g), 150-250 $\mu \mathrm{m}$ (b, e, h), and 250-355 $\mu \mathrm{m}(\mathrm{c}, \mathrm{f}, \mathrm{i})$. The ratio of polymer to $\mathrm{NaCl}$ was 1:9.

Cylinder-shaped PLLA sponges of different heights were prepared by cutting the cylinder of the polymer $/ \mathrm{NaCl}$ mixture to a specific height during the above described preparation using $150-255 \mu \mathrm{m} \mathrm{NaCl}$ particulates and a polymer $/ \mathrm{NaCl}$ ratio of 1:9. Five heights $(2,3,4,5,6$, and $7 \mathrm{~mm})$ of cylindershaped PLLA sponges were prepared to compare the effect of height on the mechanical properties.

Cylinder-shaped PLGA and PCL sponges were prepared by the same method as the cylinder-shaped PLLA sponges described above. Poly(DL-lactic-co-glycolic acid) with a copolymer ratio of 75/25 (D,L-lactic acid/glycolic acid)
(PLGA, weight-average molecular weight: 109, $520 \pm 1,670$, Sigma-Aldrich, Inc., St. Louis, MO) and poly ( $\varepsilon$-caprolactone) (PCL, weight-average molecular weight: $261,000 \pm 2800$, Sigma-Aldrich, Inc., St. Louis, MO) were used to prepare the respective cylinder-shaped PLGA and PCL sponges. The Tg of PLGA and PCL is 41 and $-56^{\circ} \mathrm{C}$, respectively [21]. Sieved $\mathrm{NaCl}$ particulates with diameter ranges of $90-150,150-250$, and $250-355 \mu \mathrm{m}$ were used. The ratio of polymer to $\mathrm{NaCl}$ particulates was $1: 9$. The sponge height was $7 \mathrm{~mm}$.

Cross-sections of the cylinder-shaped PLLA, PLGA, and PCL sponges were made by sectioning the sponges with 


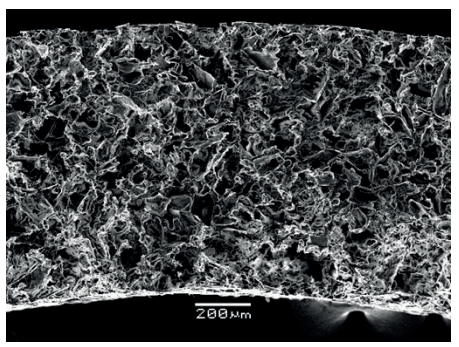

(a)

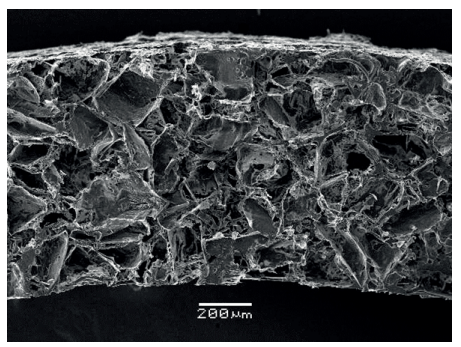

(d)

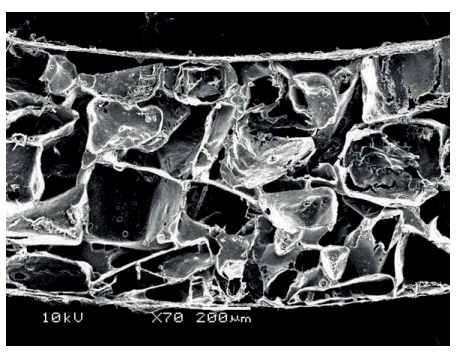

(g)

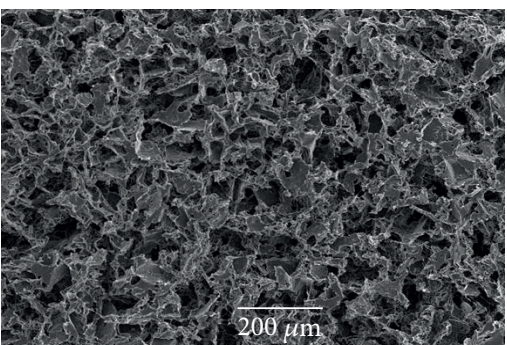

(b)

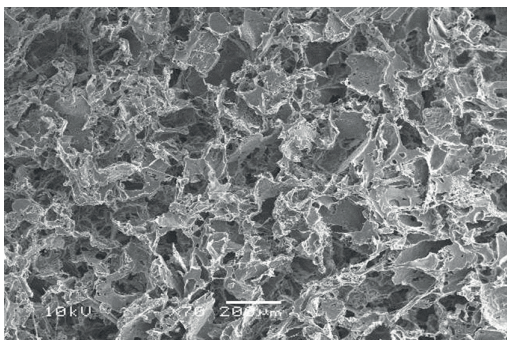

(e)

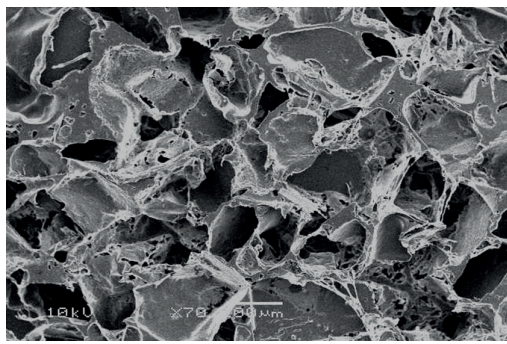

(h)

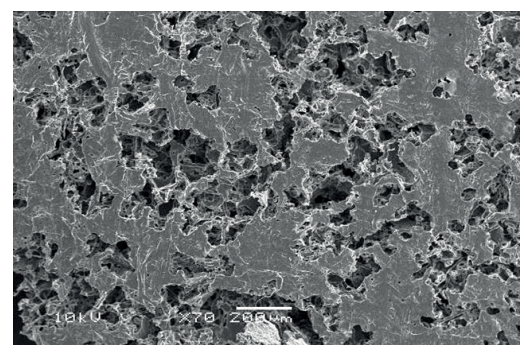

(c)

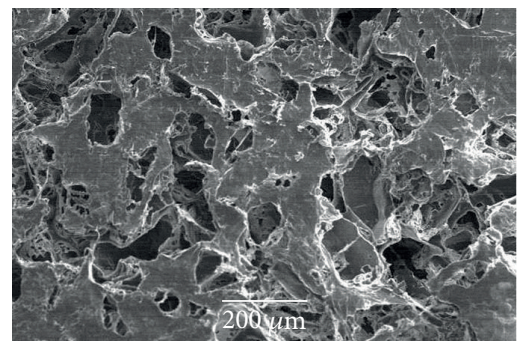

(f)

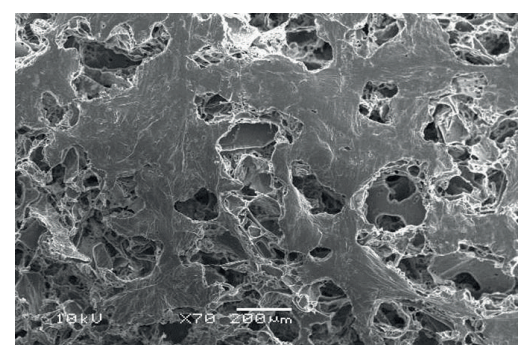

(i)

FIGURE 3: SEM microphotographs of vertical cross-sections (a, d, g), horizontal cross-sections (b, e, h), and the inner surfaces (c, f, i) of the cylinder-shaped PLLA sponges prepared with $\mathrm{NaCl}$ particulates having a diameter range of $90-150 \mu \mathrm{m}(\mathrm{a}-\mathrm{c}), 150-250 \mu \mathrm{m}(\mathrm{d}-\mathrm{f})$, and $250-355 \mu \mathrm{m}(\mathrm{g}-\mathrm{i})$. The ratio of polymer to $\mathrm{NaCl}$ was $1: 9$.

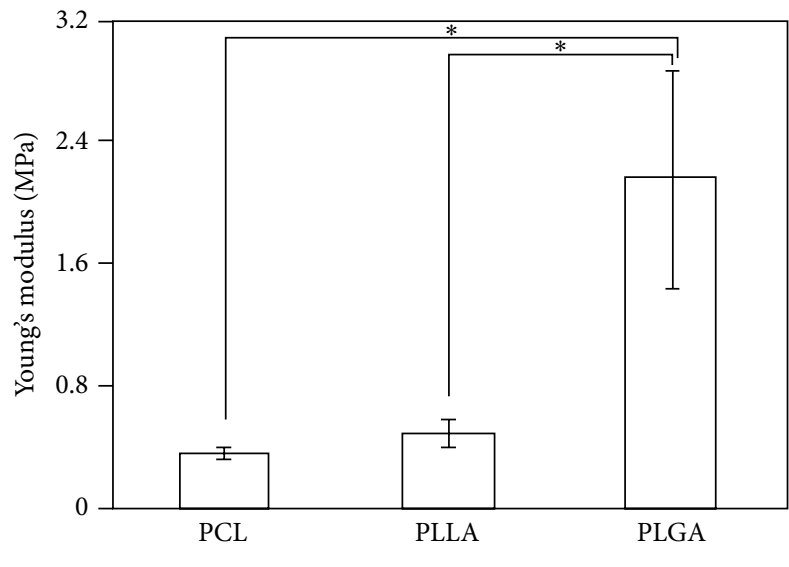

(a)

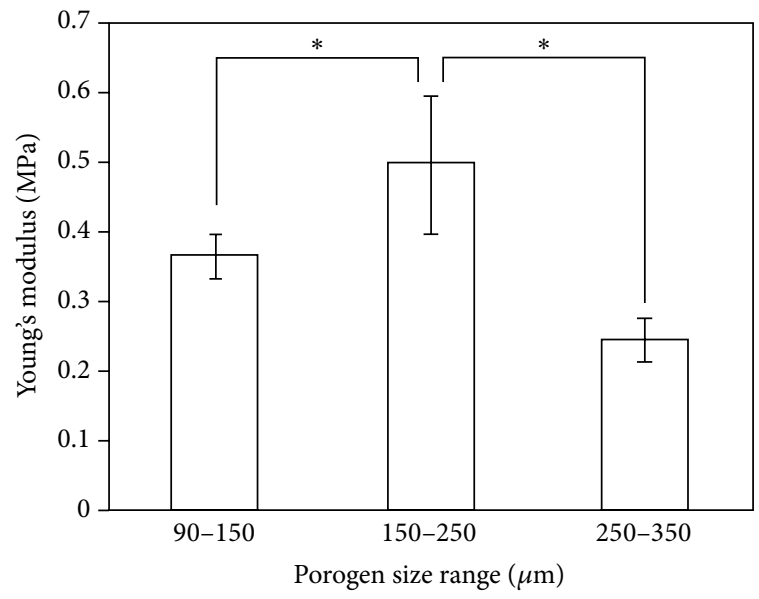

(b)

FIGURE 4: Young's modulus of cylinder-shaped PLLA, PLGA, and PCL sponges prepared with 150-250 $\mu \mathrm{m} \mathrm{NaCl} \mathrm{particulates} \mathrm{(a)} \mathrm{and} \mathrm{cylinder-}$ shaped PLLA sponges prepared with $90-150 \mu \mathrm{m}, 150-250 \mu \mathrm{m}$, and 250-355 $\mu \mathrm{m} \mathrm{NaCl}$ particulates (b). The ratio of polymer to NaCl was 1:9. The data represent the mean \pm SD of six samples. 


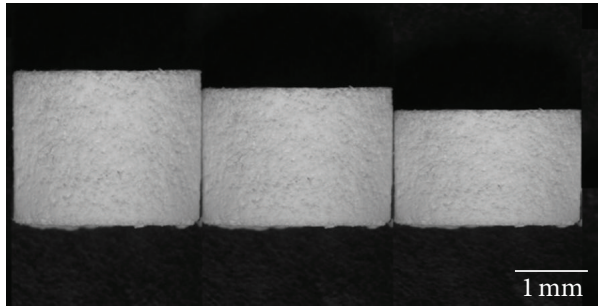

(a)

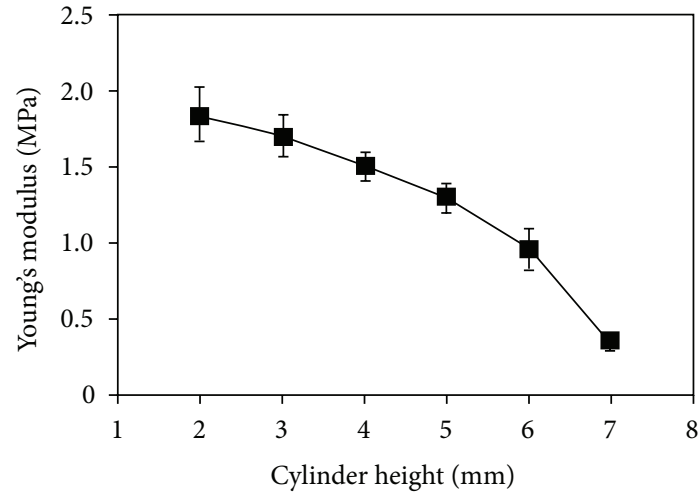

(b)

Figure 5: Photographs of cylinder-shaped PLLA sponges having a height of 7, 6, and $5 \mathrm{~mm}$ (a) and the change in Young's modulus with the sponge height $(\mathrm{b})$. The data represent the mean \pm SD of six samples.

a razor blade. The cross-section samples were coated with platinum using a sputter coater (Sanyu Denshi, Tokyo, Japan). The wall surfaces and cross-sections of the sponges were observed by scanning electron microscopy (SEM) (JSM6400Fs; JEOL, Tokyo, Japan).

A mercury porosimeter (Autopore IV, Shimadzu, Kyoto, Japan) was used to measure the porosity of the cylindershaped sponges. The sponges were cut into small pieces for the measurement.

A mechanical testing machine (TA.XTplus, Stable Micro System, UK) was used to measure the mechanical properties of the cylinder-shaped PLLA, PLGA, and PCL sponges. The dimension of each sample was measured. The dry sponges were compressed at a speed of $0.1 \mathrm{~mm} / \mathrm{min}$ at room temperature. The load-deformation curves were recorded and used to calculate the elastic modulus. The calculation was done by using the software Texture Analyzer 32 provided by the same company. A total of six samples were used for the measurements of each sponge. Data were reported as mean \pm standard deviation. One-way analysis of variance (ANOVA) was performed to reveal difference in Young's modulus among groups using the $t$-test. All statistical analyses were executed using StatFlex Ver. 4.2; $P<0.05$ was considered statistically significant.

\section{Results and Discussion}

Porous cylinder-shaped sponges of PLLA, PLGA, and PCL were prepared using a porogen leaching method. $\mathrm{NaCl}$ particulates ranging between $90-150 \mu \mathrm{m}, 150-250 \mu \mathrm{m}$, and 250-355 $\mu \mathrm{m}$ were used as the porogen materials and the ratio of polymer to $\mathrm{NaCl}$ particulates was 1:9. Figure 2 shows the gross appearance of cylinder-shaped PLLA, PLGA, and PCL sponges. The height of these cylinder-like sponges was $7 \mathrm{~mm}$. All of the sponges showed cylinder-like shape and were physically stable. The polymer type and the size of the $\mathrm{NaCl}$ particulates did not affect the gross appearance of the cylinder-shaped sponges. This method could be used to prepare cylinder-shaped sponges of different synthetic polymers by choosing the appropriate polymers.
The porous structures of the cylinder-shaped sponges were investigated by SEM observation. The SEM images of a horizontal cross-section, a vertical cross-section, and the wall surface of cylinder-shaped PLLA sponges are shown in Figure 3. All of these cylinder-shaped sponges were highly porous with evenly distributed and interconnected pore structures in the cross-sections (bulk pore structure). The pore shapes shown in the cross-sections were similar to those of $\mathrm{NaCl}$ particulates. The pore size of the cylinder-shaped PLLA sponges prepared with $90-150 \mu \mathrm{m}$, $150-250 \mu \mathrm{m}$, and $250-355 \mu \mathrm{m} \mathrm{NaCl}$ particulates increased with the size increase of the $\mathrm{NaCl}$ particulates. However, pores on the wall surfaces were fewer and smaller than those in the cross-sections. The inner wall surface and outer wall surface of the cylinder-shaped PLLA sponge showed the same pore structures.The less dense and smaller pore structure on the wall surfaces might be due to the contact effect between the $\mathrm{NaCl}$ particulates and the Teflon mold when the mixture of polymer solution and $\mathrm{NaCl}$ particulates was pressed into the Teflon mold. The angles of the cuboidallike $\mathrm{NaCl}$ particulates might contact the Teflon mold and give more space for the polymer solution to fill the spaces among the angles in contact with the Teflon mold. The structures of the inner wall and the outer wall surfaces of the cylinder-shaped sponges are expected to partially protect from cell leakage during the cell seeding and cell culture. The cylinder-shaped PLGA and PCL sponges showed similar pore structures compared to that of the cylinder-shaped PLLA sponges.

The mechanical properties of the cylinder-shaped PLLA, PCL, and PLGA sponges were measured by a compression test. The Young's modulus of cylinder-shaped PLLA, PCL, and PLGA sponges prepared with $150-250 \mu \mathrm{m} \mathrm{NaCl}$ particulates and a ratio of polymer to $\mathrm{NaCl}$ of $1: 9$ changed depending on the polymers used for the sponge preparation (Figure 4(a)). The cylinder-shaped PLGA sponge showed the highest Young's modulus, and the PCL sponge showed the lowest. PLLA is a crystalline polymer with high rigidity, while PLGA is an amorphous polymer [21]. PCL is a semicrystalline polymer and is in a rubbery state at room temperature 


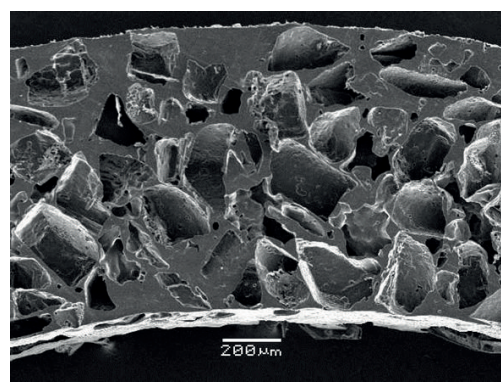

(a)

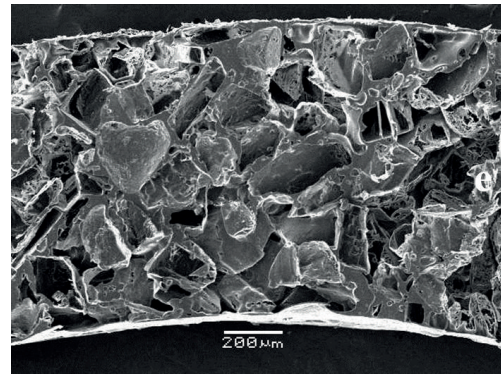

(c)

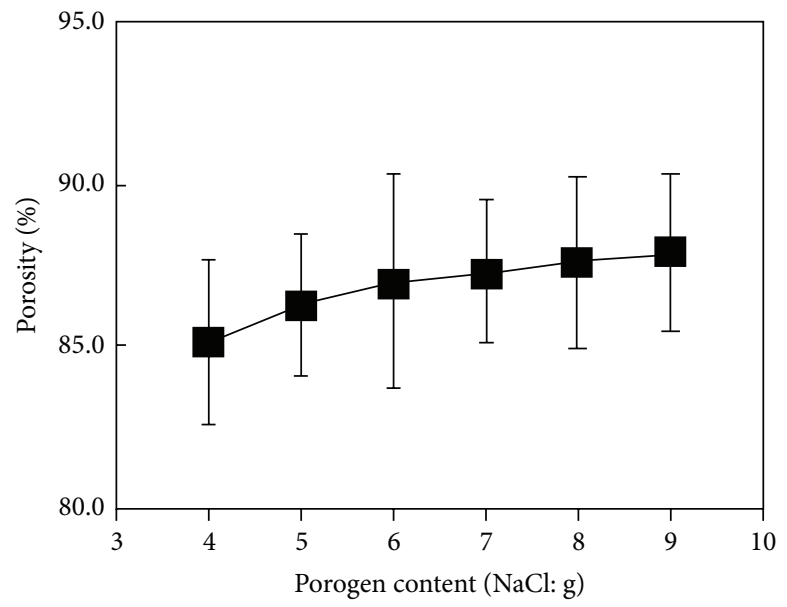

(e)

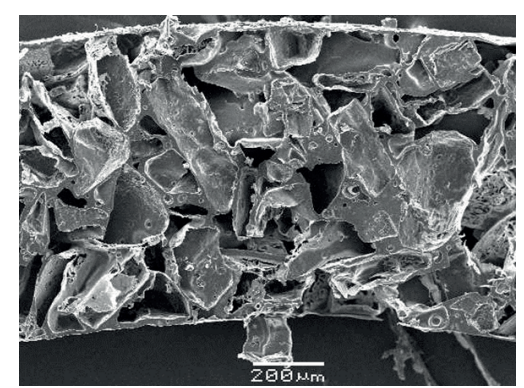

(b)

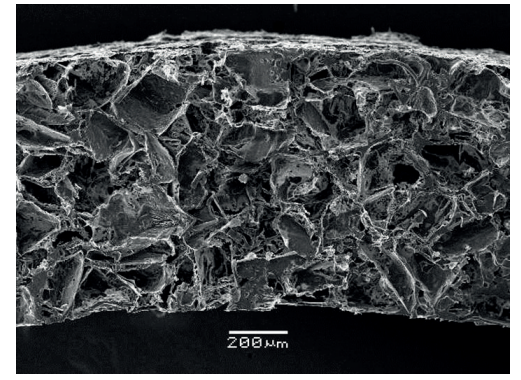

(d)

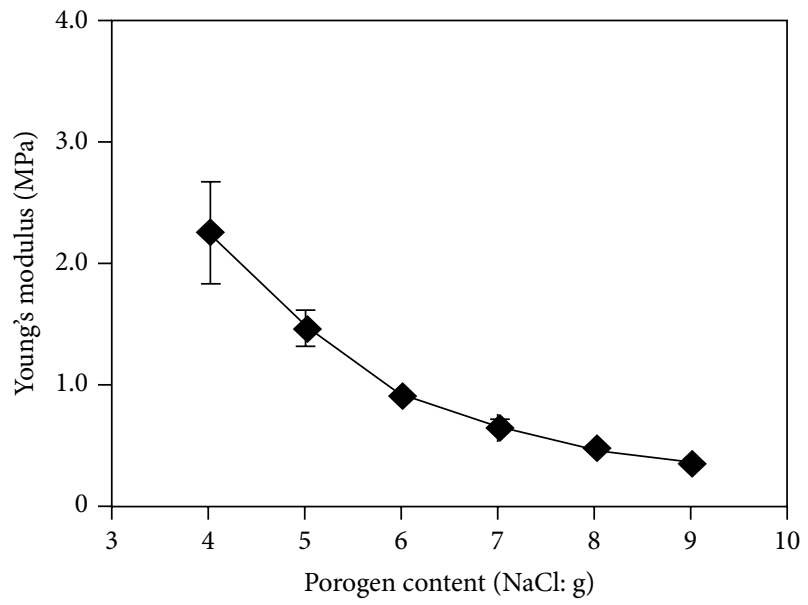

(f)

FIGURE 6: SEM microphotographs of vertical cross-sections (a-d) of the cylinder-shaped PLLA sponges prepared with $150-250 \mu \mathrm{m}$ NaCl particulates at the polymer/NaCl ratio of $1: 4$ (a), 1:5 (b), 1:6 (c) and 1:9 (d) and the change of porosity (e) and Young's modulus (f) with the polymer $/ \mathrm{NaCl}$ ratio. The porosity data represent the average \pm SD of three samples and the Young's modulus data represent the mean \pm SD of six samples.

because of its low glass transition temperature [22]. The viscoelastic property of PCL resulted in a low Young's modulus. The rigid crystalline PLLA also showed a low Young's modulus. The amorphous PLGA showed the highest Young's modulus. The low Young's modulus of cylinder-shaped PLGA sponge might be due to the difficulty in homogenous filling of PLLA/ $\mathrm{NaCl}$ mixture in the space of Teflon mold because of the high viscosity of PLLA solution.

The size of the $\mathrm{NaCl}$ particulates also showed some effect on the Young's modulus. The cylinder-shaped PLLA sponges prepared with a ratio of polymer to $\mathrm{NaCl}$ of $1: 9$ and $\mathrm{NaCl}$ particles of different sizes ranging between $90-150 \mu \mathrm{m}, 150-$ $250 \mu \mathrm{m}$, and 250-355 $\mu \mathrm{m}$ were compared (Figure 4(b)). The cylinder-shaped PLLA sponge prepared with $150-250 \mu \mathrm{m}$ $\mathrm{NaCl}$ particulates showed the highest mechanical strength, suggesting that a cylinder-like PLLA sponge with pores ranging between 150 and $250 \mu \mathrm{m}$ in size was architecturally stronger and more appropriate for applications in tissue engineering when high mechanical strength is necessary than the other tested configurations. The $\mathrm{NaCl}$ particles with sizes ranging between 150 and $250 \mu \mathrm{m}$ might be appropriately packed and polymer matrix could appropriately fill the spaces among the $\mathrm{NaCl}$ particles.

The effect of the height of the cylinder-shaped PLLA sponge on the mechanical properties was investigated. Cylinder-shaped PLLA sponges with different heights of 2, 
$3,4,5,6$, and $7 \mathrm{~mm}$ were prepared and their mechanical strengths were compared (Figure 5). The mechanical strength decreased when the height of the cylinder-like PLLA sponge increased.

The mechanical property and porosity of cylinder-shaped PLLA sponges prepared with different ratio of PLLA to $\mathrm{NaCl}$ particulates were compared. Six types of cylindershaped PLLA sponges were prepared with a weight ratio of PLLA to $\mathrm{NaCl}$ particulates of $1: 4,1: 5,1: 6,1: 7,1: 8$, and 1:9. SEM microphotographs of the cross-sections of these PLLA sponges showed that more pores were observed in the cylinder-shaped PLLA sponge prepared with a higher weight fraction of $\mathrm{NaCl}$ particulates (Figures $6(\mathrm{a})-6(\mathrm{~d})$ ). The porosity increased when the $\mathrm{NaCl}$ ratio increased (Figure 6(e)). Young's modulus decreased with the increase in $\mathrm{NaCl}$ fraction (Figure 6(f)). A high ratio of $\mathrm{NaCl}$ particulates resulted in high porosity and low mechanical strength.

Mechanically strong biodegradable synthetic polymers have been hybridized with naturally derived biodegradable polymers to construct hybrid porous scaffolds [15-19]. The hybrid porous scaffolds combine the advantages of both polymers and have been used for the tissue engineering of various tissues, such as skin [23], cartilage [24, 25], bone [26], ligament [27], bladder [19], and osteochondral tissue [28]. Use of a cylinder-shaped skeleton can improve the mechanical property and simultaneously increase the porosity to provide more space for cell accommodation [20, 29]. The preparation of such cylinder-shaped skeleton is important for the formation of the hybrid structure. In this study, the effect of polymer type, pore size, and porosity on the property of the cylinder-shaped skeleton was discussed. PLLA, PLGA, and PCL can all be used to construct the cylinder-shaped sponges, while their mechanical property was dependent on the polymer type. Polymers should be selected based on the requirements of the tissue engineering application. The pore size, porosity, and cylinder height also affected the mechanical properties. The mechanical properties can be tethered by choosing the appropriate pore size and porosity and designing the dimension of the cylinder-shaped skeletons.

\section{Conclusions}

Three biodegradable synthetic polymers, PLLA, PLGA, and PCL, were used to prepare cylinder-shaped sponges using a porogen leaching method and their properties were compared. The cylinder-shaped sponges showed a porous and interconnected structure in their bulk parts, while they were less porous with smaller pores on their surfaces. The pore size and porosity could be controlled by the size and ratio of the porogen materials. The pore size, porosity, and sponge height showed some effect on the mechanical property of the sponges. The mechanical property of the cylinder-shaped sponges was also dependent on the polymer type. The PLGA sponge showed the highest mechanical strength. Therefore, the pore structure and mechanical property of the cylindershaped sponges could be controlled by choosing the appropriate polymers and designing the preparation conditions according to the specific application in tissue engineering.

\section{Conflict of Interests}

The authors declare that there is no conflict of interests regarding the publication of this paper.

\section{Acknowledgments}

This work was supported by the World Premier International Research Center Initiative on Materials Nanoarchitectonics from the Ministry of Education, Culture, Sports, Science and Technology, Japan.

\section{References}

[1] S. J. Hollister, "Porous scaffold design for tissue engineering," Nature Materials, vol. 4, pp. 518-524, 2005.

[2] F. T. Moutos, L. E. Freed, and F. Guilak, "A biomimetic threedimensional woven composite scaffold for functional tissue engineering of cartilage," Nature Materials, vol. 6, no. 2, pp. 162$167,2007$.

[3] Y. Huang, X. Jin, X. Zhang et al., "In vitro and in vivo evaluation of akermanite bioceramics for bone regeneration," Biomaterials, vol. 30, no. 28, pp. 5041-5048, 2009.

[4] Q. Fu, Y. Hong, X. Liu, H. Fan, and X. Zhang, "A hierarchically graded bioactive scaffold bonded to titanium substrates for attachment to bone," Biomaterials, vol. 32, no. 30, pp. 7333-7346, 2011.

[5] H. Lu, T. Hoshiba, N. Kawazoe, and G. Chen, "Autologous extracellular matrix scaffolds for tissue engineering," Biomaterials, vol. 32, no. 10, pp. 2489-2499, 2011.

[6] T. Hoshiba, N. Kawazoe, T. Tateishi, and G. Chen, "Development of extracellular matrices mimicking stepwise adipogenesis of mesenchymal stem cells," Advanced Materials, vol. 22, no. 28, pp. 3042-3047, 2010.

[7] L. D. Wright, R. T. Young, T. Andric, and J. W. Freeman, "Fabrication and mechanical characterization of 3D electrospun scaffolds for tissue engineering," Biomedical Materials, vol. 5, no. 5, Article ID 055006, 2010.

[8] Y.-G. Ko, N. Kawazoe, T. Tateishi, and G. Chen, "Preparation of novel collagen sponges using an ice particulate template," Journal of Bioactive and Compatible Polymers, vol. 25, no. 4, pp. 360-373, 2010.

[9] S. C. Owen and M. S. Shoichet, "Design of three-dimensional biomimetic scaffolds," Journal of Biomedical Materials Research A, vol. 94, pp. 1321-1331, 2010.

[10] Y.-G. Ko, S. Grice, N. Kawazoe, T. Tateishi, and G. Chen, "Preparation of collagen-glycosaminoglycan sponges with open surface porous structures using ice particulate template method," Macromolecular Bioscience, vol. 10, no. 8, pp. 860-871, 2010.

[11] H. Lu, Y.-G. Ko, N. Kawazoe, and G. Chen, "Cartilage tissue engineering using funnel-like collagen sponges prepared with embossing ice particulate templates," Biomaterials, vol. 31, no. 22, pp. 5825-5835, 2010.

[12] G. Chen, T. Ushida, and T. Tateishi, "Poly(DL-lactic-co-glycolic acid) sponge hybridized with collagen microsponges and deposited apatite particulates," Journal of Biomedical Materials Research, vol. 57, no. 1, pp. 8-14, 2001.

[13] G. C. Engelmayr Jr., M. Cheng, C. J. Bettinger, J. T. Borenstein, R. Langer, and L. E. Freed, "Accordion-like honeycombs for tissue engineering of cardiac anisotropy," Nature Materials, vol. 7, no. 12, pp. 1003-1010, 2008. 
[14] I. S. Muhammad, X. Xu, and L. Li, "A review on biodegradable polymeric materials for bone tissue engineering applications," Journal of Materials Science, vol. 44, no. 21, pp. 5713-5724, 2009.

[15] W. Dai, N. Kawazoe, X. Lin, J. Dong, and G. Chen, "The influence of structural design of PLGA/collagen hybrid scaffolds in cartilage tissue engineering," Biomaterials, vol. 31, no. 8, pp. 2141-2152, 2010.

[16] M. Ananta, C. E. Aulin, J. Hilborn et al., "A poly(lactic acidco-caprolactone)-collagen hybrid for tissue engineering applications," Tissue Engineering A, vol. 15, no. 7, pp. 1667-1675, 2009.

[17] Y. Hiraoka, Y. Kimura, H. Ueda, and Y. Tabata, "Fabrication and biocompatibility of collagen sponge reinforced with poly(glycolic acid) fiber," Tissue Engineering, vol. 9, no. 6, pp. 1101-1112, 2003.

[18] Y. Takahashi, M. Yamamoto, and Y. Tabata, "Enhanced osteoinduction by controlled release of bone morphogenetic protein2 from biodegradable sponge composed of gelatin and $\beta$ tricalcium phosphate," Biomaterials, vol. 26, no. 23 , pp. $4856-$ 4865, 2005.

[19] E.-M. Engelhardt, L. A. Micol, S. Houis et al., "A collagenpoly(lactic acid-co-eopen-caprolactone) hybrid scaffold for bladder tissue regeneration," Biomaterials, vol. 32, no. 16, pp. 3969-3976, 2011.

[20] X. He, H. Lu, N. Kawazoe, T. Tateishi, and G. Chen, "A novel cylinder-type poly(L-Lactic Acid)-collagen hybrid sponge for cartilage tissue engineering," Tissue Engineering C, vol. 16, no. 3, pp. 329-338, 2010.

[21] T. Yoshioka, F. Kamada, N. Kawazoe, T. Tateishi, and G. Chen, "Structural changes and biodegradation of PLLA, PCL, and PLGA sponges during in vitro incubation," Polymer Engineering and Science, vol. 50, no. 10, pp. 1895-1903, 2010.

[22] M. A. Woodruff and D. W. Hutmacher, "The return of a forgotten polymer: polycaprolactone in the 21st century," Progress in Polymer Science, vol. 35, no. 10, pp. 1217-1256, 2010.

[23] G. Chen, T. Sato, H. Ohgushi, T. Ushida, T. Tateishi, and J. Tanaka, "Culturing of skin fibroblasts in a thin PLGA-collagen hybrid mesh," Biomaterials, vol. 26, no. 15, pp. 2559-2566, 2005.

[24] G. Chen, T. Sato, T. Ushida, N. Ochiai, and T. Tateishi, “Tissue engineering of cartilage using a hybrid scaffold of synthetic polymer and collagen," Tissue Engineering, vol. 10, no. 3-4, pp. 323-330, 2004.

[25] G. Chen, T. Sato, T. Ushida et al., "The use of a novel PLGA fiber/collagen composite web as a scaffold for engineering of articular cartilage tissue with adjustable thickness," Journal of Biomedical Materials Research A, vol. 67, no. 4, pp. 1170-1180, 2003.

[26] K. Tsuchiya, T. Mori, G. Chen et al., "Custom-shaping system for bone regeneration by seeding marrow stromal cells onto a web-like biodegradable hybrid sheet," Cell and Tissue Research, vol. 316, no. 2, pp. 141-153, 2004.

[27] G. Chen, T. Sato, M. Sakane et al., "Application of PLGAcollagen hybrid mesh for three-dimensional culture of canine anterior cruciate ligament cells," Materials Science and Engineering $C$, vol. 24, no. 6-8, pp. 861-866, 2004.

[28] G. Chen and J. Tanaka, "Osteochondral tissue engineering using a PLGA-collagen hybrid mesh," Materials Science and Engineering C, vol. 26, no. 1, pp. 124-129, 2006.

[29] N. Kawazoe, C. Inoue, T. Tateishi, and G. Chen, "A cell leakproof PLGA-collagen hybrid scaffold for cartilage tissue engineering," Biotechnology Progress, vol. 26, no. 3, pp. 819-826, 2010. 

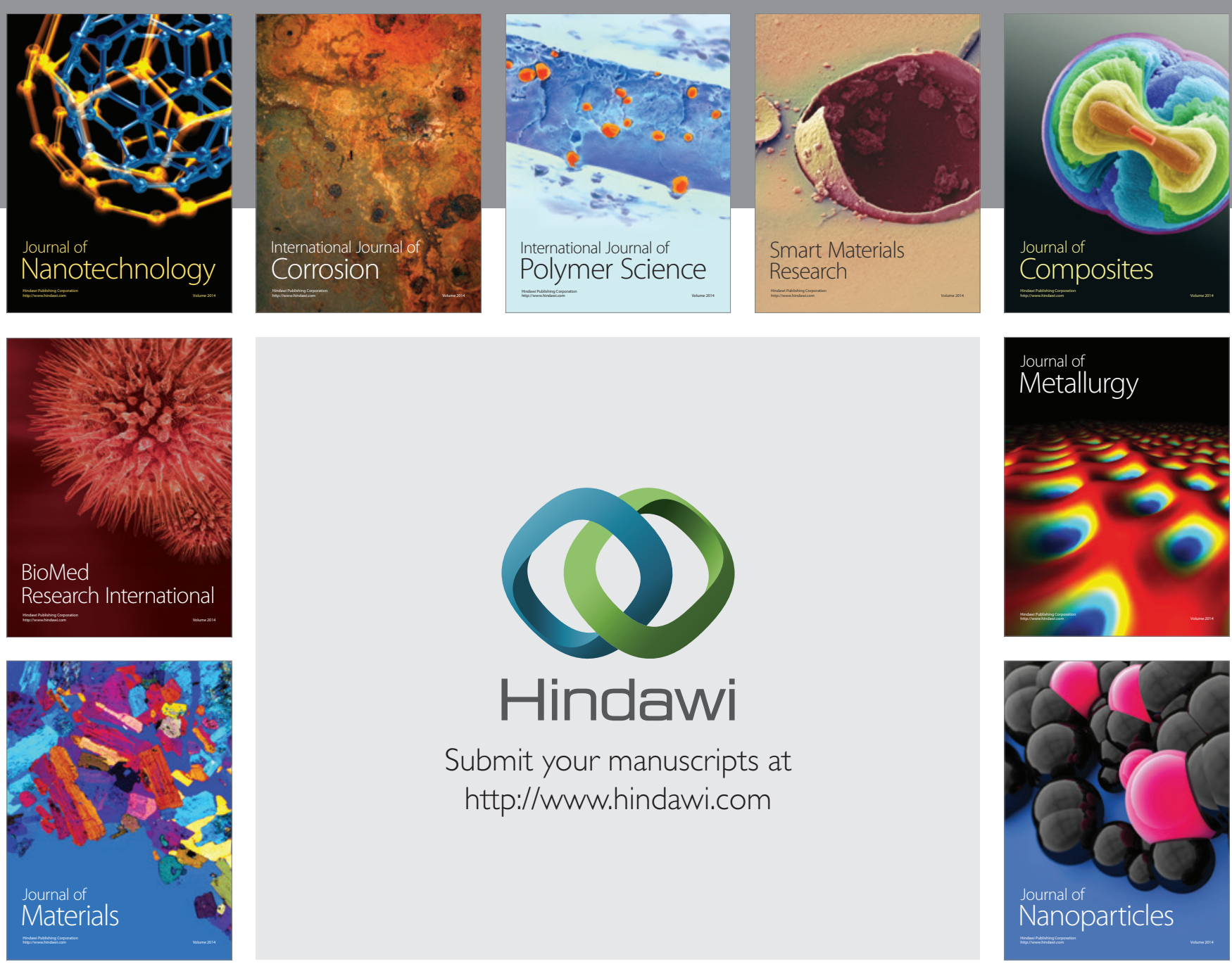

Submit your manuscripts at http://www.hindawi.com
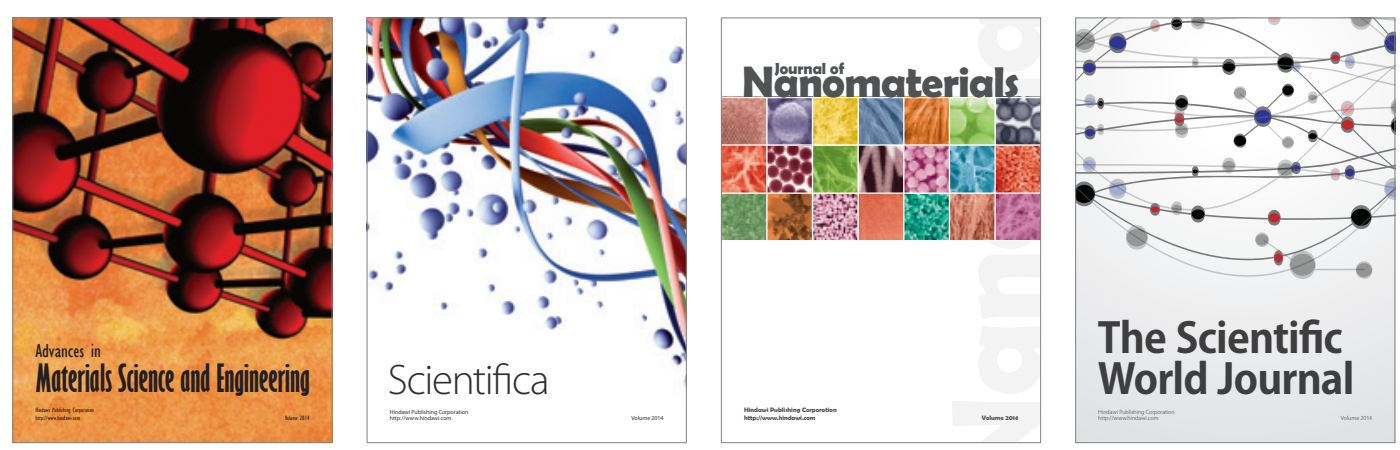

\section{The Scientific World Journal}
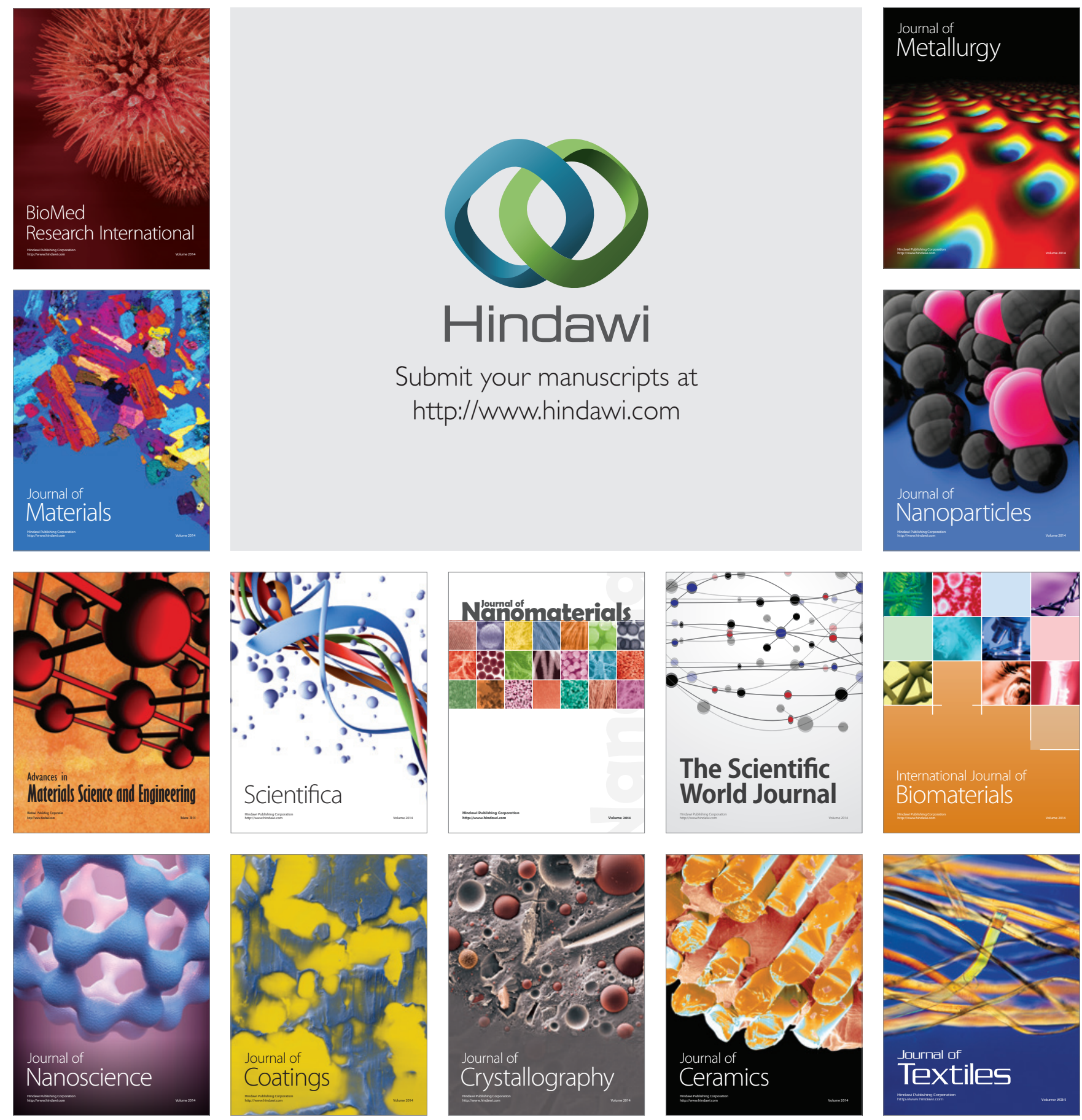